\title{
An Uncanny Partnership: Impact of Increased Awareness on Receptivity of Indian High Schoolers to Robot Teachers
}

\author{
Diyvam Arora ${ }^{1}$
}

${ }^{1}$ Bal Bharati Public School, Pitampura, Delhi, India

\begin{abstract}
$\underline{\text { ABSTRACT }}$
Robots have become an increasingly important part of our lives. They have been introduced in the education sector in the form of social robots with humanoid features that allow them to deliver lessons and interact with students. Despite the fact that research has shown that students aged 12 and below improve their learning when taught by robots and enjoy interacting with them, there are lingering concerns about their widespread use. The concerns include the lack of accountability, the impact of robots on normal socio-emotional development, and the dependence of robots on outside support. This research study aimed to assess the impact of increased awareness of the role of an assistant robot teacher in the classroom on the receptivity of high school students towards the inclusion of assistant robot teachers in the classroom. Specifically, the respondents were asked to rate their perceptions of the potential benefits of having an assistant robot teacher in the classroom before and after watching an informational video clip about an assistant robot teacher. The video clip features an Indian international school's advocacy for the deployment of an assistant robot teacher. The results showed that the video clearly had a statistically positive impact on increasing the respondents' receptivity towards having an assistant robot teacher. Based on the respondents' responses, it is evident that they were clear about the strengths (vast knowledge repository, animation, graphics) and limitations (contextual response) of the robots.
\end{abstract}

\section{Introduction}

With the rapid advances in technology, robots are becoming an increasingly prevalent part of our lives (Sharkey, 2016). Apart from having a great deal of applications in the industrial sector, robots have also been widely employed in the service sector to assist humans (Mubin et al., 2013). One of these service sectors, which are employing the use of robots, is education. It is important to point out this research study is focused on the use of 'robots' playing the roles of teachers who can interact with the students, not the ones being programmed or built by students (Sharkey, 2016).

Already, social robots introduced into the classrooms have been performing diverse functions in roles conventionally associated with human teachers. One such example is Saya, a humanoid robot resembling a female with facial expressions and a mannequin body (Hashimoto et al., 2011). Not only is she able to deliver lessons about robotics, but she is also able to manage the class by accompanying her admonishment of "Be quiet!" with the corresponding video expression (Hashimoto et al., 2011). Thanks to a video camera and Saya's CCD camera, Saya is able to transmit audio and video data in the classroom to an operator in a control room who monitors the classroom proceedings (Hashimoto et al., 2011). Similarly, Kanda et al. (2004) also described the usage of two 'Robovie' robots to expose Japanese elementary school children to interactions in English. The researchers concluded that the children who interacted more frequently with the robots actually improved their scores in English. This positive result was also replicated by Tanaka and Matsuzoe (2012) who found that the children were able to learn words better from robots than the researchers. Young children were also shown to perform better on post-learning examinations and increased 
their interest when language learning took place with the help of a robot as compared to audiotapes and books (Han et al., 2008).

Despite these positive results and the receptivity of children towards robots in the classroom, the adults' attitude towards the introduction of social robots in the classroom as teachers is far less enthusiastic. In a study conducted by Eurobarometer 382 (2012), a survey of 27,000 people in Europe revealed that 34\% thought that the usage of robots should be forbidden in education, while $60 \%$ pointed out that robots should not be allowed to take care of the vulnerable like children, the elderly and the disabled. In fact, only $3 \%$ supported their usage in the field of education.

Given the fact that teaching is an occupation that is centered upon the teachers' ability to interact and empathize with their students, as well as to adapt to them, it is hard for adults to imagine social robots being able to take the place of human beings without compromising many aspects of the teacher-student interaction (Serholt et al., 2017). Researchers have highlighted several concerns. For starters, one major ethical issue with using robots in a classroom setting is the lack of accountability (Kahn et al., 2007; Asaro, 2007). Since a robot is a machine, it cannot be blamed in case of any negative unforeseeable consequences (Kahn et al., 2007; Asaro, 2007). This thus raises the question of whether parents can be sure that their children will be in safe hands at school when a robot is in the classroom. Apart from safety concerns, robots may also undermine the development of children at an early age, as the children may begin to imitate robots and prefer to interact with them rather than with humans. As such, this could lead to their failure to develop appropriate empathy for their own kind. Previous research has shown that children can perceive robots as friends (Fior et al., 2010; Hyun et al., 2010; Kanda et al., 2004; Tanaka et al., 2007; Turkle, 2006). Still, others have criticized social robots as being fundamentally "limited, often aided by covert or even overt human intervention or remote control" (Sharkey, 2016, p. 286).

The juxtaposition of the perceived pros and cons of incorporating social robots in the classrooms certainly indicates that the jury is still out on the desirability of having robots serving as teachers within classrooms. As Sharkey (2016) pointed out, substantial research on the different roles that robot teachers can play within the classroom and their efficacy has not been carried out extensively. In truth, the adverse perceptions towards robots could essentially stem from a lack of adequate understanding of the potential benefits of the robots and the realistic expectations that one should have of them in order to harness their full potential.

Therefore, it is vital for all stakeholders, including policymakers, school leaders, teachers, students, and parents to grasp the technological capabilities of robots as teachers. They should understand how robot teachers can facilitate the teaching process, without expecting the latter to take on the aspects of teaching best served by human teachers with human capabilities.

In fact, an international school in Bengaluru in India appears to have done just that. An assistant robot teacher is able to deliver lessons in several subjects, while the human teacher sharing the same classroom space walks around the classroom to engage in one-on-one interactions with the students. Therefore, it would seem as though the human teacher and assistant robot teacher complement one another in providing a positive learning experience for the students. By using the video featuring the use of an assistant robot teacher at this school, this research study sought to assess the impact of increased awareness about the role of assistant robot teachers in the classrooms on Indian teen respondents' receptivity towards the latter's inclusion in the classroom.

\section{Description of Research Study}

\section{Research Aim and Research Approach}

The research study aimed to assess the impact of an increased understanding of the role of an assistant robot teacher in the classroom on the receptivity of high school students towards the inclusion of robot teachers in the classroom. Specifically, respondents, high school students, in India were asked to rate their perceptions of the benefits of having 
an assistant robot teacher in the classroom before and after watching an informational video clip about an assistant robot teacher. The video clip features an Indian international school's advocacy for the employment of an assistant robot teacher.

A mixed-method research approach was adopted for this research study. First, a quantitative approach was adopted to measure the differences between the ratings of the high schoolers' attitude towards robot teachers before and after watching the video clip.

The hypotheses that were tested were as follows:

- Null Hypothesis: The informational clip on assistant robots has no effect on the attitude of high school students towards the use of robot teachers in the classroom.

- Alternative hypothesis: The informational clip has an effect on the attitude of high school students towards the use of robot teachers in the classroom.

In addition, a qualitative data approach was also used to assess the impact of the video on the respondents' perceptions about the role of assistant robot teachers in their classroom. The qualitative data also provided the reasoning underlying the respondents' ratings for a particular question, thus allowing for a deeper analysis of the quantitative data.

\section{Sampling}

An online survey was conducted with fifty-five 11th and 12th graders from a high school in Delhi. They were contacted via WhatsApp class groups with the approval of the school's Vice-Principal (see Appendix A for the "Participation Invitation Letter"). Upon receiving the survey form, the respondents were required to watch the video and fill the survey form in a home setting. An in-person survey couldn't be conducted due to lockdown in the country; however, the study can be replicated in controlled conditions with more number of subjects and a monitored setting to get more accurate results. High school students were targeted as they were likely to have perspectives that were representative of future generations of students who could experience having assistant robot teachers in the classroom.

\section{Data Collection}

Data were collected through a self-formulated questionnaire (see Appendix B). Respondents were asked to rate their perceptions of the following statements concerning the benefits of having assistant robot teachers in the classroom before and after watching the video clip. A 5-point rating scale was used, with "1" being "Strongly Disagree" and "5" being "Strongly Agree". The statements being evaluated were as follows:

1. A robot teacher can improve the quality of instruction in the classroom.

2. A robot teacher can support the human teacher in the classroom.

3. A robot teacher can teach all subjects.

4. A robot teacher can help to enhance the classroom performance of the students.

5. A robot teacher would help to improve my interest in the subject.

6. I would like to have an assistant robot teacher teaching me in my class.

Each of these statements was deliberately tailored to match the information pertaining to the informational video clip about the introduction of robots in a school in Bengaluru, India. Essentially, any changes in the perceptions towards the potential assistant robot teacher would reveal the impact of the video in influencing the students' perceptions towards the use of the assistant robot teacher. 
The video offers a concise introduction of a female robot teacher delivering a lecture on Chemistry teaching a class of middle school students at an international school. She could also answer subject-specific questions using the programmed lessons or referring to the Internet to address the queries of the students. According to the school leaders, the key benefit of having an assistant robot teacher was in enabling the human teacher to focus on the well-being of the students. The school leaders who have invested in the assistant robot teacher also pointed out that in order for teachers to focus on the education of the heart and mind of the children, their workload has to be reduced. A manmachine team of a human teacher and an assistant robot teacher could significantly improve the efficiency of teaching in schools. For instance, as one teacher pointed out, the robot teacher could take over the more rote aspects of a teacher's function such as delivering a lecture on a topic. In the meantime, she could commit more time and energy to interact with individual students. In fact, a male teacher was shown in the classroom walking from student to student to check on their work, while the robot teacher was delivering the lesson. Students also seemed happy with the robot teacher in the classroom as they got a better visual learning experience through the use of graphics and animations.

Apart from the statements that elicited quantitative ratings, the respondents could also offer their reasoning for their ratings in order to gather richer data for further analysis. Each statement was followed by a question that requested for the respondents' rationale for their ratings.

\section{Data Analysis}

Descriptive statistics were done to determine whether there were changes in the overall attitude of the respondents before and after watching the video in general and with regards to the robot teachers' individual contributions to teaching efficiency, student performance, teaching assistance, and quality of instruction in the classroom. Corresponding paired t-tests were conducted to determine whether the changes in the ratings of the respondents (if any) vis-a-vis their attitude towards robot teachers in the classroom were statistically significant. Finally, the respondents' responses to open-ended questions explaining their ratings were used to provide further interpretations of the quantitative data.

\section{Results and Findings}

In this chapter, all the results from the statistical analyses, as outlined in the "Description of Research Study" section, are presented and examined in detail. The effects of an increased understanding of the role of an assistant robot teacher in the classroom on the attitude of high school students towards the inclusion of robot teachers in the classroom are addressed and discussed.

The overall mean ratings of the respondents towards the inclusion of robot teachers in the classroom were compared by deriving the overall mean of their ratings towards the six questions before and after watching the video clip. As shown in Table 1, the overall mean rating of the respondents' receptivity towards including robot teachers in the classroom after watching the video clip $(M=3.61, S D=.93)$ was higher than their overall mean rating before watching the video clip $(M=3.26, S D=.86)$ by 0.35 . 
Table 1: Descriptive Statistics on the Overall Mean Ratings of the Respondents

\begin{tabular}{|c|c|c|c|}
\hline BEFORE & & AFTER & \\
\hline Mean & 3.26363636 & Mean & 3.60909091 \\
\hline Standard Error & 0.11586553 & Standard Error & 0.12596193 \\
\hline Median & 3.16666667 & Median & 3.66666667 \\
\hline Mode & 3 & Mode & 3.33333333 \\
\hline Standard Deviation & 0.85928175 & Standard Deviation & 0.93415869 \\
\hline
\end{tabular}

To determine whether the change in the overall pre and post-video mean ratings are statistically significant, a paired sample t-test was run. As shown in Table 2, the result shows statistical significance: $t(54)=4.84$ (higher than the critical value of 2.00), $p<.01$ (two-tailed).

Table 2: Paired Sample T-Test for Overall Mean Ratings

\begin{tabular}{|c|c|c|}
\hline & Before & After \\
\hline Mean & 3.263636364 & 3.60909091 \\
\hline Variance & 0.738365133 & 0.87265245 \\
\hline Observations & 55 & 55 \\
\hline Pearson Correlation & 0.829277869 & \\
\hline Hypothesized Mean Difference & 0 & \\
\hline df & 54 & \\
\hline t Stat & -4.844367582 & \\
\hline $\mathrm{P}(\mathrm{T}<=\mathrm{t})$ one-tail & $5.5465 \mathrm{E}-06$ & \\
\hline t Critical one-tail & 1.673564906 & \\
\hline $\mathrm{P}(\mathrm{T}<=\mathrm{t})$ two-tail & $1.1093 \mathrm{E}-05$ & \\
\hline t Critical two-tail & 2.004879288 & \\
\hline
\end{tabular}


The above-average initial rating of 3.26 to 3.61 suggests that the respondents were already rather receptive towards having an assistant robot teacher. This would seem to confirm the general literature that indicates the younger generations' receptivity towards social robots. The statistically significant increase in the overall mean rating of 0.35 thus suggests that the video did exert a positive impact on their receptivity towards assistant robot teachers.

In order to have a more precise understanding of the reactions of the respondents, the changes in the mean ratings of the respondents' answers to each question that addresses how the robot assistant teacher could be beneficial in a classroom before and after watching the video clip will also be presented and discussed.

\section{Quality of Instruction}

The respondents' mean rating of the effectiveness of an assistant robot assistant in improving the quality of instruction $(M=3.33, S D=1.22)$ increased by 0.66 after watching the video clip, as compared to before $(M=2.67, S D=1.25$; see Table 3).

Table 3: Descriptive Statistics on Pre- and Post-Video Ratings of Quality of Instruction

\begin{tabular}{|c|c|c|}
\hline & Before & After \\
\hline Mean & 2.67272727 & 3.32727273 \\
\hline Standard Error & 0.16828416 & 0.16423385 \\
\hline Median & 3 & 3 \\
\hline Mode & 3 & 3 \\
\hline Standard Deviation & 1.24802875 & 1.21799084 \\
\hline
\end{tabular}

To determine whether the change in the pre- and post-video mean ratings for improvement in the quality of instruction is statistically significant, a paired sample t-test was run. As shown in Table 4, the result shows statistical significance: $t(54)=4.31$ (higher than the critical value of 2.00), $p<.01$ (two-tailed).

Table 4: Paired Sample T-Test for Pre- and Post-Video Ratings of Improvement of Quality of Instruction

\begin{tabular}{|c|c|c|}
\hline & Before & After \\
\hline Mean & 2.672727273 & 3.32727273 \\
\hline Variance & 1.557575758 & 1.48350168 \\
\hline Observations & 55 & 55 \\
\hline Pearson Correlation & 0.583432624 & \\
\hline
\end{tabular}




\begin{tabular}{|c|c|l|}
\hline Hypothesized Mean Difference & 0 & \\
\hline $\mathrm{df}$ & 54 & \\
\hline $\mathrm{t}$ Stat & -4.31195851 & \\
\hline $\mathrm{P}(\mathrm{T}<=\mathrm{t})$ one-tail & $3.45718 \mathrm{E}-05$ & \\
\hline $\mathrm{t}$ Critical one-tail & 1.673564906 & \\
\hline $\mathrm{P}(\mathrm{T}<=\mathrm{t})$ two-tail & $6.91435 \mathrm{E}-05$ & \\
\hline $\mathrm{t}$ Critical two-tail & 2.004879288 & \\
\hline
\end{tabular}

By examining the mean ratings, one can see that the respondents were initially skeptical about the ability of the assistant robot teacher in improving the quality of the instruction. However, after watching the video, they were substantially more impressed by the capabilities of the robot to contribute to the improvement of the quality of the instruction. In fact, out of the 55 respondents, 24 of them rated the statement that an assistant robot teacher can improve the quality of instruction " 3 " or below changed it to " 4 " or " 5 " after watching the video.

Upon looking at the video, the robot being talked about can be really good at instruction in the classroom as it is pretty responsive and uses the technology efficiently.

As seen in the video, the robot helps the teacher in developing interesting tools for imparting education.

A robot is filled with data and has unlimited knowledge that may help students learn things better and in different ways.

At the same time, there were 26 respondents whose perceptions about the assistant robot teachers' contribution in this area did not change after watching the video. A key factor lies in the respondents' perceptions that the assistant robot teacher's lack of flexibility and adaptability to the needs of individual students:

In my opinion, an actual human teacher is better equipped to handle the doubts of the students as they can change the language of the text to suit the needs of the child. In the case of a robot, there is fixed content that is available to the robot.

I stand with my answer as before. A robot cannot differentiate between students. For the robot, all students are on the same level and not unique like a teacher looks at them. A robot can never judge the mental and physical presence of a student in the classroom and adapt to the situation like a human teacher.

\section{Support for Human Teachers}

The respondents' mean rating on the effectiveness of an assistant robot teacher in supporting the human teacher in a classroom $(M=4.07, S D=1.14)$ decreased by 0.11 after watching the video clip, as compared to before $(M=4.18$, $S D=0.92 ;$ see Table 5). 
Table 5: Descriptive Statistics for Pre- and Post-Video Ratings of Support for Human Teachers

\begin{tabular}{|c|c|c|}
\hline & Before & After \\
\hline Mean & 4.18181818 & 4.07272727 \\
\hline Standard Error & 0.12469737 & 0.15320272 \\
\hline Median & 4 & 4 \\
\hline Mode & 5 & 5 \\
\hline Standard Deviation & 0.92478044 & 1.1361818 \\
\hline
\end{tabular}

To determine whether the change in the pre and post-video mean ratings are statistically significant, a paired sample t-test was run. As shown in Table 6, the result shows that factor is statistically insignificant: $t(54)=0.92, p=.36$ (twotailed).

Table 6: Paired Sample T-Test for Pre- and Post-Video Ratings of Support for Human Teachers

\begin{tabular}{|c|c|c|}
\hline & Before & After \\
\hline Mean & 4.18181818 & 4.07272727 \\
\hline Variance & 0.85521886 & 1.29090909 \\
\hline Observations & 55 & 55 \\
\hline Pearson Correlation & 0.65691768 & \\
\hline Hypothesized Mean Difference & 0 & \\
\hline df & 54 & \\
\hline t Stat & 0.92459789 & \\
\hline $\mathrm{P}(\mathrm{T}<=\mathrm{t})$ one-tail & 0.17964429 & \\
\hline t Critical one-tail & 1.67356491 & \\
\hline $\mathrm{P}(\mathrm{T}<=\mathrm{t})$ two-tail & 0.35928858 & \\
\hline t Critical two-tail & 2.00487929 & \\
\hline
\end{tabular}




\section{Effectiveness in Teaching All Subjects}

The respondents' mean rating on the ability of a robot teacher to effectively teach all subjects $(M=3.50, S D=1.40)$ increased by 0.32 after watching the video clip, as compared to before $(M=3.18, S D=1.28$; see Table 7$)$.

Table 7: Descriptive Statistics for Pre- and Post-Video Ratings of Teaching Effectiveness of All Subjects

\begin{tabular}{|c|c|c|}
\hline & Before & After \\
\hline Mean & 3.18181818 & 3.49090909 \\
\hline Standard Error & 0.17231032 & 0.18869163 \\
\hline Median & 3 & 4 \\
\hline Mode & 3 & 5 \\
\hline Standard Deviation & 1.27788757 & 1.39937456 \\
\hline
\end{tabular}

To determine whether the change in the pre and post-video mean ratings are statistically significant, a paired sample t-test was run. As shown in Table 8, the result shows that factor is statistically insignificant: $t(54)=1.76, p=0.08$ (two-tailed).

Table 8: Paired Sample T-Test for Pre- and Post-Video Ratings of Teaching Effectiveness of All Subjects

\begin{tabular}{|c|c|c|}
\hline & Before & After \\
\hline Mean & 3.18181818 & 3.49090909 \\
\hline Variance & 1.63299663 & 1.95824916 \\
\hline Observations & 55 & 55 \\
\hline Pearson Correlation & 0.52908232 & \\
\hline Hypothesized Mean Difference & 0 & \\
\hline df & 54 & \\
\hline $\mathrm{t}$ Stat & -1.7586207 & \\
\hline $\mathrm{P}(\mathrm{T}<=\mathrm{t})$ one-tail & 0.04215389 & \\
\hline
\end{tabular}




\begin{tabular}{|c|l|l|}
\hline t Critical one-tail & 1.67356491 & \\
\hline $\mathrm{P}(\mathrm{T}<=\mathrm{t})$ two-tail & 0.08430778 & \\
\hline $\mathrm{t}$ Critical two-tail & 2.00487929 & \\
\hline
\end{tabular}

\section{Improvement of Students' Classroom Performance}

The respondents' mean rating of the effectiveness of an assistant robot teacher in improving the classroom performance of students $(M=3.6, S D=1.16)$ increased by 0.45 after watching the video clip, as compared to before $(M=$ $3.15, S D=1.15$; see Table 9).

Table 9: Descriptive Statistics for Pre- and Post-Video Ratings of Improvement in Classroom Performance

\begin{tabular}{|c|c|c|}
\hline & Before & After \\
\hline Mean & 3.14545455 & 3.6 \\
\hline Standard Error & 0.15443648 & 0.15699193 \\
\hline Median & 3 & 4 \\
\hline Mode & 3 & 3 \\
\hline Standard Deviation & 1.14533162 & 1.16428328 \\
\hline
\end{tabular}

To determine whether the change in the pre and post-video mean ratings are statistically significant, a paired sample t-test was run. As shown in Table 10, the result shows statistical significance: $t(54)=3.32$ (higher than the critical value of 2.00), $p<0.01$ (two-tailed).

Table 10: Paired Sample T-Test for Pre- and Post-Video Ratings of Improvement in Classroom Performance

\begin{tabular}{|c|c|c|}
\hline & Before & After \\
\hline Mean & 3.14545455 & 3.6 \\
\hline Variance & 1.31178451 & 1.35555556 \\
\hline Observations & 55 & 55 \\
\hline Pearson Correlation & 0.61381656 & \\
\hline
\end{tabular}




\begin{tabular}{|c|c|l|} 
Hypothesized Mean Difference & 0 & \\
\hline $\mathrm{df}$ & 54 & \\
\hline $\mathrm{t}$ Stat & -3.3210558 & \\
\hline $\mathrm{P}(\mathrm{T}<=\mathrm{t})$ one-tail & 0.00080637 & \\
\hline $\mathrm{t} \mathrm{Critical}$ one-tail & 1.67356491 & \\
\hline $\mathrm{P}(\mathrm{T}<=\mathrm{t})$ two-tail & 0.00161274 & \\
\hline
\end{tabular}

By closely studying the qualitative data, it was observed that the opinions of the respondents can be broadly divided into four categories. According to the survey results, a set of 29 respondents, after watching the video, were found to believe that the inclusion of an assistant robot teacher in a classroom could improve the classroom performance of students, whether directly or indirectly. They felt that an assistant robot could help to reduce the workload of the human teacher, which would enable the human teacher to pay attention to them closely and solve their doubts. Interestingly, the respondents also stated that they would feel comfortable with sharing their doubts with a robot teacher over a human teacher due to the reduced risk of bias. This complex perspective is captured by the responses below:

A robot can be there for doubts when the students find excuses to not reach out to the teacher. It can act as an assistant to a human teacher and complete multiple tasks which will, in fact, make the teacher feel less stressed out and he/she will be able to give his/her $100 \%$ in each session. It can also complete the tasks that are repetitive for the teacher and takes their precious time away in the blink of an eye. It will make the students look forward to their tasks because the amount of attention-to-detail a robot can provide beats the human skills.

Students can express their views to robots in an unbiased way. They won't fear the repercussions of openly expressing their ideas. This will enhance student's critical thinking.

Another set of 19 respondents was neutral about the inclusion of a robot teacher in the classroom as a means of improving their performance. The following response actually shows how the respondent perceived that any benefits introduced by the robot would be annulled by its deficits:

Students would probably not pay much attention to the robot teachers as there wouldn't be the fear of being scolded. Also, there would be less understanding of the subject. At the same time, a robot teacher can be made to work according to the speed of learning of the child and hence improve their performance.

It seems as though the respondents perceived that the authority of the role of the teacher would be eroded, as a 'robot' would not be perceived with the same respect that students typically accord to human teachers. Rather, it would simply be a useful tool that could be used by students. Another respondent in this group also argued that a student's classroom performance is ultimately more dependent on the student than the nature of the teacher:

Not sure about that, but I think it depends a lot on the child itself, rather than who is teaching, whether it's a robot or a human teacher. 
However, for 15 respondents, it is the absence of an emotional connection that limits a robot's capacity to improve a student's classroom performance of students.

A robot teacher cannot help to increase student performance because for a student, feelings and emotions are much more important than just mugging up things. A friendly relation can be built only between a human and human and not with human and machine

[The robots] can't enhance the performance as robots can't understand the students' emotions and psychology. [The robots] play a great role in enhancing performance.

\section{Improvement of Interest}

The respondents' mean rating on the effectiveness of an assistant robot teacher in improvement of their interest in a particular subject $(M=3.22, S D=1.21)$ increased by 0.35 after watching the video clip, as compared to before $(M=$ $2.87, S D=1.38$; see Table 11).

Table 11: Descriptive Statistics for Pre- and Post-Video Ratings of Improvement of Interest

\begin{tabular}{|c|c|c|c|}
\hline Q5 Before & & Q5 After & \\
\hline Mean & 2.87272727 & Mean & 3.21818182 \\
\hline Standard Error & 0.18541889 & Standard Error & 0.16348665 \\
\hline Median & 3 & Median & 3 \\
\hline Mode & 3 & Mode & 3 \\
\hline Standard Deviation & 1.3751033 & Standard Deviation & 1.21244945 \\
\hline
\end{tabular}

To determine whether the change in the pre and post-video mean ratings are statistically significant, a paired sample t-test was run. As shown in Table 12, the result shows statistical significance: $t(54)=2.89$ (Higher than the critical value of 2.00), $p<0.01$ (two-tailed).

Table 12: Paired Sample T-Test for Pre- and Post-Video Ratings of Improvement of Interest

\begin{tabular}{|c|c|c|}
\hline & Before & After \\
\hline Mean & 2.87272727 & 3.21818182 \\
\hline Variance & 1.89090909 & 1.47003367 \\
\hline Observations & 55 & 55 \\
\hline
\end{tabular}




\begin{tabular}{|c|c|l|}
\hline Pearson Correlation & 0.77225809 & \\
\hline Hypothesized Mean Difference & 0 & \\
\hline $\mathrm{df}$ & 54 & \\
\hline $\mathrm{t}$ Stat & -2.8900147 & \\
\hline $\mathrm{P}(\mathrm{T}<=\mathrm{t})$ one-tail & 0.00276827 & \\
\hline $\mathrm{t}$ Critical one-tail & 1.67356491 & \\
\hline $\mathrm{P}(\mathrm{T}<=\mathrm{t})$ two-tail & 0.00553654 & \\
\hline $\mathrm{t}$ Critical two-tail & 2.00487929 & \\
\hline
\end{tabular}

By examining the quantitative data, it can be seen that before watching the video, around 16 respondents were skeptical about the notion that a robot teacher can help to improve their interest in a particular subject. However, after watching the video, their opinion changed. As the video presented the robot teacher assisting the human teacher in teaching and using graphics and animations, the respondents were able to see that the robot could improve their engagement with the subject through the employment of appropriate graphics and animations. The respondents also felt that the robot has access to endless information and can clear all of their doubts to a great extent.

It is quite a unique concept and matches the interest of students of today's generation. Most of the students are tech geeks and will feel interested in their process of education... This concept will create a more impactful process of human interaction.

... a robot full of knowledge from subjects to human nature... can use its knowledge to give interesting lessons which people will like, i.e., it can make the lessons to be presented in such a way to make it interesting by its own creativity.

The presentations, diagrams, graphs and other data shared, along with the content provided under the assistance of a human teacher, would improve my interest.

Even though most of the people got optimistic about the idea that robots can improve their interest in the subject after watching the video, around 15 respondents still believed that a robot teacher won't be able to improve their interest in a particular subject. They felt that effective teaching is associated with an emotional connection and deep intellectual discussions and debates, which are beyond the capabilities of a robot, as shown below:

Personally, I believe in deep discussions and debates to arouse my interest in a particular subject; so I don't think robots can improve my interest.

As reasoned above, the teacher can use personal anecdotes and short stories to make the students feel connected, but the robot might not be able to do that. The robot might just give standard information and not any extra interesting things which the students want to know.

I don't think so because a robot is a machine without emotions. And humans have a better ability to communicate with humans and expand their interest in specific topics. 


\section{Desire for Assistant Robot Teachers}

The respondents' mean rating of the desire for an assistant robot teacher to be included in a classroom $(M=3.95, S D$ $=1.21)$ increased by 0.42 after watching the video clip, as compared to before $(M=3.53, S D=1.36$; see Table 13$)$.

Table 13: Descriptive Statistics for Pre- and Post-Video Ratings of Desire for Robot Teachers

\begin{tabular}{|c|c|c|c|}
\hline Q6 Before & & Q6 After & \\
\hline Mean & 3.52727273 & Mean & 3.94545455 \\
\hline Standard Error & 0.18322687 & Standard Error & 0.162924 \\
\hline Median & 4 & Median & 4 \\
\hline Mode & 5 & Mode & 5 \\
\hline Standard Deviation & 1.35884681 & Standard Deviation & 1.20827673 \\
\hline
\end{tabular}

To determine whether the change in the pre and post-video mean ratings are statistically significant, a paired sample t-test was run. As shown in Table 14, the result shows statistical significance: $t(54)=3.01$ (Higher than the critical value of 2.00), $p<0.01$ (two-tailed).

Table 14: Paired Sample T-Test for Pre- and Post-Video Ratings of Desire for Robot Teachers

\begin{tabular}{|c|c|c|}
\hline & Before & After \\
\hline Mean & 3.52727273 & 3.94545455 \\
\hline Variance & 1.84646465 & 1.45993266 \\
\hline Observations & 55 & 55 \\
\hline Pearson Correlation & 0.68330033 & \\
\hline Hypothesized Mean Difference & 0 & \\
\hline df & 54 & \\
\hline t Stat & -3.008543 & \\
\hline P $<$ ) one-tail & 0.00199101 & \\
\hline
\end{tabular}




\begin{tabular}{|c|l|l|}
$\mathrm{t}$ Critical one-tail & 1.67356491 & \\
\hline $\mathrm{P}(\mathrm{T}<=\mathrm{t})$ two-tail & 0.00398202 & \\
\hline $\mathrm{t}$ Critical two-tail & 2.00487929 & \\
\hline
\end{tabular}

The fact that 38 respondents increased their desire to have an assistant robot teacher in the classroom after watching the video attests to the fact that the video did exert an overall positive impact in getting Indian teens to be interested at the prospect of an assistant robot teacher in the classroom. The statistically significant increase in the mean rating from 3.53 to 3.94 suggests two things: 1) a relatively high level of receptivity towards robots to begin with among the Indian teens; and 2) a slight increase in the level of receptivity after watching the video. The pre-video results show that the respondents were keen on the idea of having an innovative and interesting technology introduced into a classroom setting. The increase in the rating after the watching of the video reaffirms this fact.

\section{Conclusion}

The findings of the research study show that a video, even one as short as 3 minutes, can be sufficiently effective to significantly increase the respondents' level of receptivity towards having an assistant robot teacher in the classroom. In general, the null hypothesis that the informational clip on assistant robots has no effect on the receptivity of high school students towards the use of robot teachers in the classroom can be rejected. On the whole, the respondents' receptivity towards having an assistant robot teacher in their classroom, based on the mean rating of the six questions posed to them, increased by 0.35 after watching the video clip.

More specifically, by analyzing the statistical significance of the increases in the mean ratings with regards to specific areas, the study demonstrated that the greatest statistically significant increases are in the interrelated areas of quality of instruction (0.66) and students' classroom performance (0.45). In fact, these results were also supported by the respondents' comments that honed in on the perceived strengths of the assistant robot's teacher vis-à-vis those of a human teacher: reservoir of knowledge, animated and graphical features, as well as emotional objectivity. Essentially, they considered the assistant robot teacher to be a good complement for the human teacher to reinforce their learning experience, as addressed in the following quotes:

The robot will probably be able to substantiate what my teacher is trying to teach and help me out with the facts and doubts that need detailed attention and definitely enhance the classroom experience.

I would love to have an assistant robot in the class, since this will allow me to ask any question fearlessly, even if it is very basic. This way, teachers won't have to spend their time answering questions that have already been answered before.

Similarly, here, an assistant robot would make me more interested in school education. It will create an impact on me and make me more interested in the session. If we are honest, I personally do not like to devote tedious hours in studying, but it'll make me more involved in studies due to this interesting process.

Robot teacher as an assistant would make the teacher focus on students who need some special attention. There would be greater one-to-one interaction. 
These responses clearly attest to the effectiveness of the video in conveying to the respondents the benefits of having an assistant robot teacher in a clearly-demarcated role with responsibilities that take into accounts its strengths and limitations, which can allow it to be a good partner with a human teacher.

At the same time, it is important to point out that the respondents' overall receptivity towards the assistant robot teacher was tempered by their recognition that it would not be a replacement for human teachers. They strongly believe that robots would not be able to make a strong emotional connection with students. This is clearly evident in the responses to the question pertaining to whether a robot teacher will be effective in teaching all subjects. The majority of the respondents believed that a robot teacher can only teach STEM subjects efficiently because these subjects require only logical reasoning and analysis and limited understanding of human emotions. Their stance remained the same before and after watching the video.

Certain subjects like English require some storytelling and sharing anecdotes, which would lose its charm when an emotionless robot does so.

A robot teacher can teach all subjects, however, not efficiently, because as I said earlier, it doesn't have the emotional aptitude for teaching subjects like Psychology or Social Sciences or theoretical subjects, where we need more than just statistics and facts, rather experiences, examples, different perspectives and discussions.

I feel where robots can make things easier and the education process more precise and accurate. [However,] socially and emotionally interactive sessions are not possible with them. And for me, it's one of the things I look forward to during classroom teaching, the discussions, debates and pondering over things.

A robot teacher can help in teaching STEM subjects. However, it might be hard to teach social sciences, since it involves a lot more emotional connection with the students.

This research study certainly illuminates the effectiveness of increasing awareness about the role that an assistant robot teacher plays in the classroom in promoting students' receptivity towards robot teachers. Moreover, this research study reveals that it isn't difficult to generate awareness. A carefully chosen video clip that sets out clearly the employment of the robot and its benefits is sufficient in provoking the thinking of the respondents about what an assistant robot teacher can do.

In addition, the survey that not only elicited a quantitative rating about the different areas in which the assistant robot teachers are supposed to be helpful in, as determined from the video, but also their responses to open-ended questions, gave further insights into their thinking underlying their responses. As a result, the research study was able to reveal the extent of the respondents' knowledge and preconceived notions about the capabilities of assistant robot teachers. These responses also demonstrated clearly whether they understood the message conveyed by the video.

Furthermore, unlike previous studies that focused on the interactions between the robot teacher and children primary school children (Broadbent et al., 2018; Serholt et al., 2017), or surveyed adults (Serholt et al., 2017; Ahmad et al., 2016), this research study targeted respondents aged 16 and above. They were close in age to the students in the video and shared common subjects with them, thus making the video even more relatable to the students. The respondents could thus easily imagine how an assistant robot teacher could be used to teach the subjects that they, too, were studying. Therefore, this research study contributed to the discourse on the perceptions of the use of robots in classrooms by bringing in the perspectives of Indian teens who were mature and IT-savvy enough to appreciate robots and consider the larger implications of robots.

Finally, the qualitative responses of the respondents in this research study also reveals what the respondents really like about the idea of having an assistant robot teacher: ability to give lectures, ability to solve doubts, effective use graphics and animations for teaching, correcting mark sheets, distributing papers, etc. Given the fact that companies like SoftBank Robotics and Hanson Robotics are constantly trying to improve their current robots with better 
emotional understanding by making them more human-like (ResearchandMarkets.com, 2020), they may want to reconsider other areas of focus. Within the context of education, the robots fundamentally cannot exceed the human teacher in 'human-like' characteristics. It may thus be more worthwhile to focus on the assistant teacher's strengths and accept their non-human-like characteristics as part of what makes it novel to have a robot as a teacher in the classroom in the first place. This research report can indirectly help these corporations to identify the weaknesses in their products by understanding what the customer is expecting.

Based on the rapid progress in technology, with robotics becoming an increasingly prominent field (Sharkey, 2016), it is a matter of time before robots permeate into every sphere of our lives. While it is evident that social robots in the field of education can be effective in improving the learning experience of IT-savvy our younger generations who seem to take to them well (Serholt et al., 2017; Sharkey 2016), it is important to remain cognizant of their potentially negative effects. Given the concerns over the safety, accountability and social development of children (Serholt et al., 2017), it would be wise for all stakeholders, particularly school leaders, educational professionals and policymakers, to incorporate social robots in the field of education thoughtfully in order not to jeopardize their viability in the classroom.

What the video has convincingly shown is that most of the ethical concerns raised in the introduction can be minimized by setting appropriate parameters around the usage of the robots. The school featured in the video certainly provides an exemplary path forward in their gradual adoption of the assistant robot in a collaborative partnership with a human teacher working next to it. Here are some recommendations for how assistant robot teachers can be safely deployed within the classroom to offer an optimal learning experience, based on what is currently known:

- Usage of assistant robot teachers with more mature age groups of at least nine years and above: As discussed earlier, one of the key concerns is the long-term effects of social interaction with the robot and the development of social skills in children (Serholt et al., 2017; Sharkey, 2016). However, this need not be the case, if the children were older and had a sufficiently clear appreciation of the differences between human and robotic interactions.

- Inclusion of a human teacher working in tandem with an assistant robot teacher: The aforementioned concern would also be addressed by the fact that a human teacher would always be present to counteract the effects of a robot teacher. Essentially, the students would always have a human teacher to interact with, not to mention the presence of their peers.

- Optimization of the features of an assistant robot teacher: Unlike a human teacher, an assistant robot teacher can store vast reservoir of knowledge, as well as amazing graphics and animation. As such, they are able to supplement the human teacher in offering a stimulating multi-sensory learning experience, while always being able to come up with the correct answers.

- Support for the teacher: By taking over some of the more mundane and routine chores for teachers, which include administrative work, delivering lessons, hand out question papers and collecting answer sheets, or even correcting multiple-choice tests, the assistant robot teacher can free up time for the human teacher for other areas of teaching work. The human teacher can offer one-on-one attention on the students' well-being, conduct discussions that involve critical thinking and adaptability, correct essays, and formulate curriculum suggestions, among other endeavours.

Even though this study could not be conducted in a monitored environment due to the COVID-19 outbreak, its methodology can be easily replicated with a larger sample size and controlled conditions, including a physical demonstration of the robot to obtain generalizable results. Nonetheless, the analysis of data collected from the current survey reveals that assistant robots teachers have the potential to improve the overall learning experience of students. Furthermore, it would seem that students are largely receptive to the idea of trying them out in the classroom. The onus thus falls on school leaders and educational professionals, along with policymakers, the support staff, and manufacturers to make sure that they can be introduced successfully into the classroom setting. 


\section{References}

Ahmad, M. I., Mubin, O., \& Orlando, J. (2016). Understanding behaviours and roles for social and adaptive robots in education: Teacher's perspective. HAI'16: Proceedings of the Fourth International Conference on Human Agent Interaction, pp. 297-304. https://doi.org/10.1145/2974804.2974829.

Asaro, P. M. (2007). Robots and responsibility from a legal perspective. https://pdfs.semanticscholar.org/427c/27a48205293fe59b94898ba1d266b4b3ea89.pdf? ga=2.2713264.1227056274.1593793635$\underline{1674252892.1592925793}$

Broadbent, E., Feerst, D. A., Lee, S. H., Robinson, H., Albo-Canals, J., Ahn, H. S., \& Macdonald, B. (2018). How could companion robots be useful in rural schools? International Journal of Social Robotics, 10(3), 295-307. https://doi.org/10.1007/s12369-017-0460-5

Eurobarometer 382. (2012). Public attitudes towards robots. Brussels: European Commission.

Fior, M., Nugent, S., Beran, T. N., Ramirez-Serrano, A., \& Kuzyk, R. (2010). Children's relationships with robots: Robot is child's new friend. Journal of Physical Agents, 4, 9-17.

Hashimoto, T., Kato, N., \& Kobayashi, H. (2011). Development of educational system with the android robot SAYA and evaluation. International Journal Advanced Robotic Systems, 8(3), 51-61.

Hyun, E., Yoon, H., \& Son, S. (2010) Relationships between user experiences and children's perceptions of the education robot. Paper presented at the Proceedings of the 5th ACM/IEEE International Conference on Human-Robot interaction, Osaka, Japan. https://doi.org/10.1109/HRI.2010.5453197

Han, J., Jo, M., Jones, V., Jo, \& J.H. (2008). Comparative study on the educational use of home robots for children. Journal of Information Processing Systems, 4(4), 159-168.

Kanda, T., Hirano, T., Eaton, D., \& Ishiguro, H. (2004). Interactive robots as social partners and peer tutors for children: A field trial. Human-Computer Interaction, 19, 61-84.

Kahn, P. H., Ishiguro, H., Friedman, B., Kanda, T., Freier, N. G., Severson, R. L., \& Miller J (2007) What is a human? Toward psychological benchmarks in the field of human-robot interaction. Interaction Studies, 8, 363-390.

Mubin, O., Stevens, C. J., Shadid, S., Al Mahmud, A., \& Dong, J. J. (2013). A review of the applicability of robots in education. Technology for Education and Learning, 1, 1-7. https://doi.org/10.2316/Journal.209.2013.1.209-0015

ResearchAndMarkets.com. (2020). Educational robot market - Growth, trends, and forecast (2020-2025). Author.

Serholt, S., Barendregt, W., Vasalou, A., \& Alves-Olveira, P. (2017). The case of classroom robots: Teachers' deliberations on the ethical tensions. AI \& Society, 32(4), 613-631. https://doi.org/ 10.1007/s00146-016-0667-2

Sharkey, A. J. C. (2016). Should we welcome robot teachers? Ethics of Information Technology, 18, 283-297

https://doi.org/10.1007/s10676-016-9387-z 
Tanaka, F., Cicourel, A., \& Movellan, J. R. (2007) Socialization between toddlers and robots at an early childhood education center. Proceedings of the National Academy of Sciences, 104, 17954-17958.

https//doi:org/10.1073/pnas.0707769104

Tanaka, F., \& Matsuzoe, S. (2012). Children teach a care-receiving robot to promote their learning: Field experiments in a classroom for vocabulary learning. Journal of Human-Robot Interaction, 1(1), 78-95.

Turkle, S. (2006). A nascent robotics culture: New complicities for companionship. AAAI Technical Report Series, 2006. http://web.mit.edu/ sturkle/www/nascentroboticsculture.pdf 